\title{
Observed development of the vertical structure of the marine boundary layer during the LASIE experiment in the Ligurian Sea
}

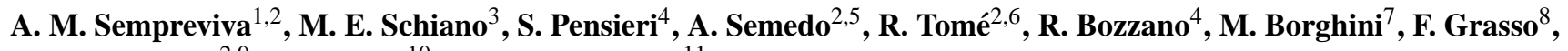 \\ L. L. Soerensen ${ }^{2,9}$, J. Teixeira ${ }^{10}$, and C. Transerici ${ }^{11}$ \\ ${ }^{1}$ CNR-ISAC, Zona Industriale di Lamezia Terme, 88046 Lamezia Terme, Italy \\ ${ }^{2}$ Risoe - DTU, Frederiksbogvej 399, 4000, Roskilde, Denmark, Roskilde, Denmark \\ ${ }^{3}$ CNR-ISMAR, via De Marini 6, 16149 Genova, Italy \\ ${ }^{4}$ CNR-ISSIA, via De Marini 6, 16149 Genova, Italy \\ ${ }^{5}$ Dep. Earth Sciences, University of Uppsala, 75182 Uppsala, Sweden \\ ${ }^{6}$ Centro do Clima, Meteorologia e Mudanças Globais, Azores University, Angra do Heroísmo, 97100 Terceira, Portugal \\ ${ }^{7}$ CNR-ISMAR, Forte S.Teresa Pozzuolo di Lerici, 19100 La Spezia, Italy \\ ${ }^{8}$ CNR-ISAC, Str. Prov. Lecce Monteroni Km 1,200, 73100 Lecce, Italy \\ ${ }^{9}$ National Environmental Research Institute, University of Aarhus, Frederiksbogvej 399, 4000, Roskilde, Denmark \\ ${ }^{10}$ Jet Propulsion Laboratory, California Institute of Technology, 4800 Oak Grove Drive, MS 169-237 Pasadena, CA 91109 , \\ USA \\ ${ }^{11}$ CNR-ISAC, Via del Fosso del Cavaliere 100, 00133 Rome, Italy
}

Received: 20 July 2009 - Revised: 30 November 2009 - Accepted: 8 December 2009 - Published: 8 January 2010

\begin{abstract}
In the marine environment, complete datasets describing the surface layer and the vertical structure of the Marine Atmospheric Boundary Layer (MABL), through its entire depth, are less frequent than over land, due to the high cost of measuring campaigns. During the seven days of the Ligurian Air-Sea Interaction Experiment (LASIE), organized by the NATO Undersea Research Centre (NURC) in the Mediterranean Sea, extensive in situ and remote sensing measurements were collected from instruments placed on a spar buoy and a ship. Standard surface meteorological measurements were collected by meteorological sensors mounted on the buoy ODAS Italia1 located in the centre of the Gulf of Genoa. The evolution of the height $\left(z_{i}\right)$ of the MABL was monitored using radiosondes and a ceilometer on board of the N/O Urania.

Here, we present the database and an uncommon case study of the evolution of the vertical structure of the MABL, observed by two independent measuring systems: the ceilometer and radiosondes. Following the changes of surface flow conditions, in a sequence of onshore - offshore onshore wind direction shifting episodes, during the mid part of the campaign, the overall structure of the MABL changed.
\end{abstract}

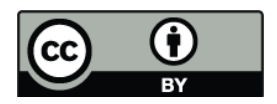

Correspondence to: A. M. Sempreviva (am.sempreviva@isac.cnr.it)
Warm and dry air from land advected over a colder sea, induced a stably stratified Internal Boundary Layer (IBL) and a consequent change in the structure of the vertical profiles of potential temperature and relative humidity.

Keywords. Atmospheric composition and structure (Transmission and scattering of radiation)

\section{Introduction}

The Atmospheric Boundary Layer (ABL) is defined as the part of the atmosphere directly influenced by the Earth's surface, often responding with a time scale of about one hour or less (Stull, 1988). The depth of the ABL $\left(z_{i}\right)$ varies in time and space according to the forcing by surface fluxes of momentum, and sensible and latent heat. The ABL top is usually identified by a sharp increase in the potential temperature $\left(T_{\mathrm{p}}\right)$ vertical profile (called inversion), and a decrease in humidity, that characterize the Free Atmosphere (FA). The layer closer to the surface, typically about $10 \%$ of the $z_{i}$, is called the Surface Layer (SL). The layering above the SL depends on the surface atmospheric stability conditions, i.e. stable, unstable and neutral. The evolution of the height of the ABL over land and over the sea is caused by different mechanisms. Over land, the daily solar radiation cycle leads to a well recognized picture of the evolution of

Published by Copernicus Publications on behalf of the European Geosciences Union. 
the vertical structure of the ABL (Stull, 1988): after sunrise, the sun warms up the Earth's surface, the heat is transferred by molecular diffusion to a thin layer of air above the ground, and then further transported upward by rising plumes of warm air (thermals) deepening the ABL. Two layers can be identified: the mixed layer (ML), and the entrainment zone (EZ) where potentially warm and dry air is entrained from the FA. After sunset, the release of surface heat by long-wave radiation induces a ground based inversion in the potential temperature vertical profile, leading to a stable SL. Upward motion is suppressed and the ABL is shallow; however, above this ground based inversion, a second inversion is often found indicating the presence of the so called Residual Layer (RL) from the previous day ML. The surface layer flow is called neutral when the surface heat and moisture fluxes are close to zero and the ABL mixing is only governed by mechanical turbulence. Over the ocean the AML is often called Marine Atmospheric Boundary Layer (MABL). In the marine environment, due to the high thermal capacity of the water body, the surface fluxes and the evolution of the vertical structure of the MABL depend on several factors, mainly the geographic location (open ocean, coastal waters, enclosed seas) and the synoptic conditions. In coastal areas, during offshore flow, an Internal Boundary Layer (IBL) develops from the coastal discontinuity, and eventually merges with the oceanic atmospheric boundary layer further offshore. Garratt and Ryan (1989) presented the development of a stable IBL of the coast of southeast Australia, during an offshore outbreak of warm and dry air from land. Using radiosoundings and aircraft measurements they compared $T_{\mathrm{p}}$ ground-based inversions detected at three distances from coast, showing that a stable IBL could be found up to $300 \mathrm{~km}$ offshore. Above the ground based inversion, they found a ML explained by warm dry air advected from land.

During the last decade, the depth of the ABL has been progressively recognized as playing a key role in the surface layer turbulence structure, and the interplay of processes at different spatial and temporal scales (Sempreviva and Gryning, 2000; Smedman et al., 2007; Katul et al., 2008; Larsen and Sempreviva, 2008). Recently, Gryning et al. (2007) suggested that the wind profile above $50-80 \mathrm{~m}$ height is controlled by the surface conditions, the height of the ABL, and the conditions above the boundary layer, in the FA. Also, the amount of water in the air partly depends on the inversion height, affecting the evaporation from the sea surface as well as the cloud formation (Gryning et al., 2002). Moreover, the transmission of radar and microwave signals over the ocean may be disturbed by the layered structure and height of the MABL (Brooks et al., 1999).

To achieve a detailed characterization of the mean vertical structure of the MABL, and of the turbulent fluxes at the airsea interface, extensive ship- and buoy- based meteorological and oceanographic observations must be carried out by in-situ and remote sensing devices. However, due to the tech- nical and environmental difficulties, along with high costs, a complete set of measurements, spanning from the surface throughout the entire MABL, are rare. Therefore, most of the studies have been carried out mainly from coastal locations at the shoreline and/or from islands (Sempreviva and Gryning, 2000; Helmis, 2007; Edson et al., 2007; Smedman et al., 2007).

The intensive Ligurian Sea Air-Sea Interaction Experiment (LASIE), carried out from 16 to 23 June 2007, in the Mediterranean Sea (Teixeira, 2007), was organized under the auspices of the NATO Undersea Research Centre (NURC), located in La Spezia, Italy, with the participation of several European research centres. The main scientific goal of this field campaign was to contribute to the evaluation and development of parameterizations of the oceanic and atmospheric boundary layers and their interaction. Therefore, the LASIE campaign was designed to provide one of the few comprehensive air-sea measurement campaigns carried out in the Mediterranean Sea area, which plays a crucial role as source of energy and moisture for the European Climate. The Mediterranean area is a transitional zone between the subtropical desert area of North Africa and the continental regions of Central and North Europe. Therefore, its climate regime shows both mid-latitude and tropical aspects (Schiano et al., 2005). In addition, the surrounding orography of this enclosed basin is greatly complicated by the presence of steep high mountains along its Northern coastline, along with large mountainous islands, having a strong influence in the general regional atmospheric circulation, and also producing local intense phenomena. Because of these peculiarities, the atmospheric and marine features of this basin are very different from those of the open ocean, particularly for what concerns the amount of water vapour at the atmospheric surface (Schiano et al., 2000). The Ligurian Sea is the most inland sea of the Mediterranean; the northern part is bounded by Alps, and the Southern part by the Corsica Island. These steep orographic features, and the thermal contrast between land and sea, give rise to specific local effects that influence the circulation of both atmosphere and ocean. Particular processes in this area are, for example, the Genoa cyclogenesis, where low pressure systems develop South of the Alps, and local conditions, which are responsible for intense convection phenomena, often leading to extreme precipitation along the coastal areas (Kelsh et al., 2001).

The purpose of this paper is twofold: to draw the attention of the scientific community to this unique database; and to focus on the atmospheric part of the database presenting a particular case study of synoptic-driven time evolution of the MABL structure in the cruise area. We follow the response of the vertical structure of temperature and humidity in the MABL during a sequence of onshore - offshore - onshore flow event, affecting the stability conditions at the surface. In Sect. 2, we introduce the experimental setup, the exploited database and the applied methodologies; in Sect. 3, we present the case study of the evolution of the vertical 


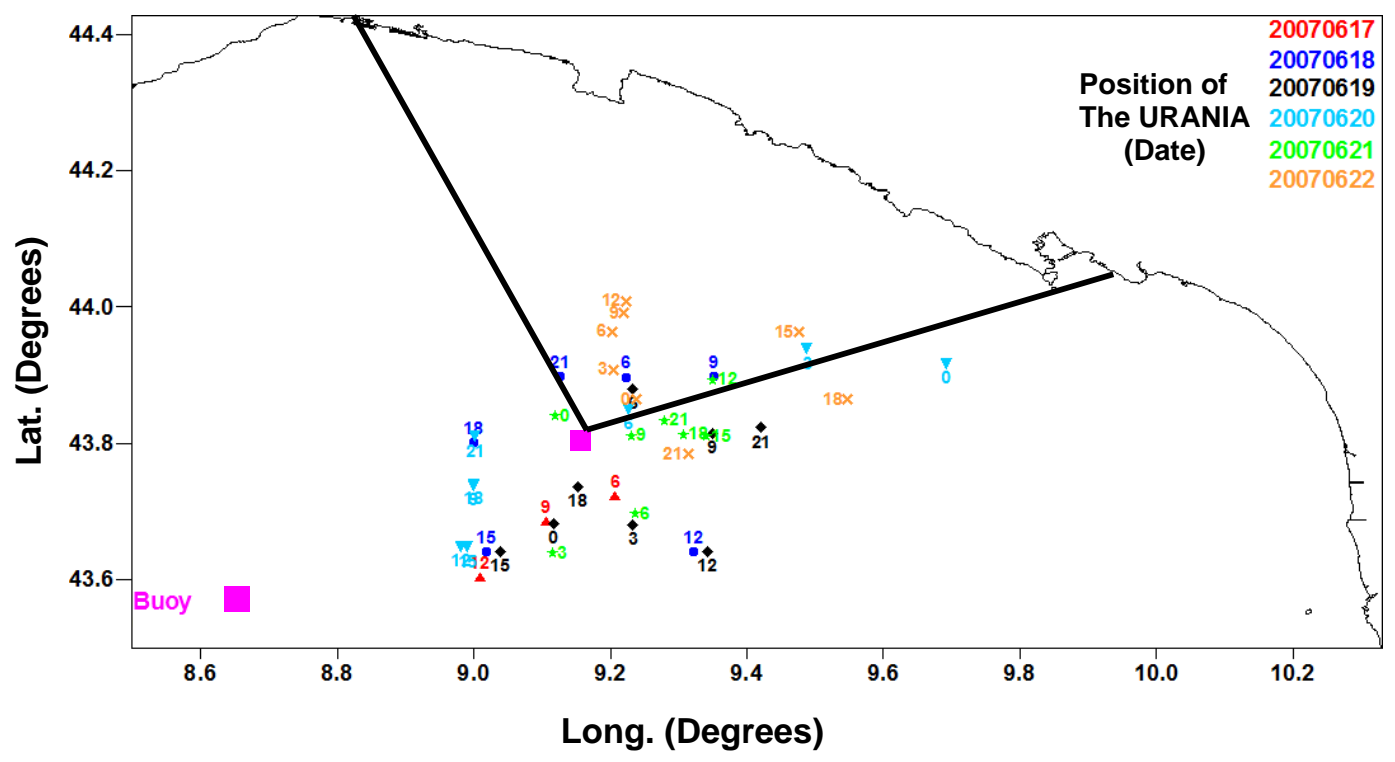

Fig. 1. Urania operational areas during LASIE. Day 21 and 22 the ship was sailing within large areas back and forth from and to the cost. The black lines delimit the "land" sector with outflow from the coast.

structure of the MABL; and in Sect. 4, we present our final remarks.

\section{The experimental setup and methodology}

We use the atmospheric observations collected at the CNR ODAS Italia 1 spar buoy, and from the CNR N/O URANIA research vessel, from 16 to 23 June 2007. During this period, the ship was stationed either in a small area in the vicinity of the buoy position, or between the buoy and the coast (Fig. 1). The ODAS Italia 1 spar buoy is moored in the Ligurian Sea (Fig. 1) at $43^{\circ} 47.36^{\prime} \mathrm{N}, 009^{\circ} 09.80^{\prime} \mathrm{E}$, about $73 \mathrm{~km}$ off Genoa, at a water depth of $1377 \mathrm{~m}$ (Nittis, 2007). The buoy weighs about $11 \mathrm{t}$, has a small laboratory built at the top, and has a design (e.g. total mass, unity buoyancy at sea level and damping disk) such as sensitivity to sea heave is negligible (Bertaux, 1976; Cavaleri et al., 1981). The buoy is equipped with an acquisition system that collects data from the meteorological and marine sensors. The sampled records are transferred in real time by a satellite phone link to the shore station, where they are quality checked. During LASIE, the ODAS Italia 1 acquisition system routinely collected the atmospheric and marine parameters, shown in Table 1 , at a frequency $f$ of $0.2 \mathrm{~Hz}$. Particularly, wind speed $U$ $\left(\mathrm{m} \mathrm{s}^{-1}\right)$ and wind direction DIR (degrees) were recorded by a bi-dimensional sonic anemometer mounted at $14.4 \mathrm{~m}$ height, while solar and atmospheric radiation $\left(\mathrm{W} \mathrm{m}^{-2}\right)$ sensors were mounted on the bulk of the structure. In order to measure and control the data quality, two sensors were used for air temperature $T_{\mathrm{a}}\left({ }^{\circ} \mathrm{C}\right)$, atmospheric pressure $P(\mathrm{hPa})$ and relative humidity $\mathrm{RH}(\%)$, while the sea surface temperature $T_{\mathrm{S}}\left({ }^{\circ} \mathrm{C}\right)$ was obtained by SBE 39 probes, mounted at different depths. The SBE-39 is a temperature recorder with an extremely accurate and precise thermistor (its drift is less than $0.002^{\circ} \mathrm{C}$ per year). All probes installed on the ODAS buoy during the LASIE experiment have a ruggenized thermistor, embedded in a titanium end cap, and sample in an autonomous way every $15 \mathrm{~min}$.

At the same time, the development of the vertical structure of the MABL was monitored by radiosondes, using the Vaisala DigiCORA Sounding System MW21, and by a ceilometer Vaisala CL31. The radiosondes were launched from the main deck, about $2 \mathrm{~m}$ above the sea surface, every $3 \mathrm{~h}$, recording vertical profiles of $P, U$, DIR, $T_{\mathrm{a}}$ and RH, vertical profiles of the potential temperature were derived by

$T_{\mathrm{p}}=T\left(\frac{P_{0}}{P}\right)^{\frac{R}{c_{p}}}$

where $P_{0}$ is the pressure at the $1000 \mathrm{hPa}, R$ is the gas constant of air, and $c_{p}$ is the specific heat at constant pressure.

The ceilometer was mounted on the upper deck, about $8 \mathrm{~m}$ above the sea level, and was continuously recording at a frequency of $0.2 \mathrm{~Hz}$. Seibert et al. (2000) reviewed the most used algorithms for determining the height of the MABL using vertical profiles of $T_{\mathrm{p}}, \mathrm{RH}, U$ and DIR, by radiosondings. However, when the number of radiosondings is limited, the visual examination of the profiles is performed to identify the height of the inversions (Sempreviva and Gryning, 2000; Gryning et al., 2002; Hennemuth and Lammert, 2006; Helmis, 2007). In Fig. 2, as an example of the procedure, profiles of $T_{\mathrm{p}}$ and RH are shown for 21 June at 15:00 GMT. Here, the inversion that forms the top of the mixed layer can be recognized at a height of about $900 \mathrm{~m}$, above this lower 
Table 1. Equipment on the ODAS Italia 1 buoy.

\begin{tabular}{lccc}
\hline Parameter & Manufacturer & Model & Height/depth [m] \\
\hline & Meteorological measurements & \\
\hline Global solar radiation & Eppley & PSP & +14.6 \\
Infrared solar radiation & Eppley & PYR & +14.6 \\
Wind speed & Gill & WindSonic & +14.4 \\
Wind direction & Gill & WindSonic & +14.4 \\
Air temperature & Vaisala & HMP45A & +14.3 \\
Relative humidity & Vaisala & HMP45A & +14.3 \\
Atmospheric pressure & Vaisala & PTB100A & +7.8 \\
Air temperature & Vaisala & WXT510 & +14.5 \\
Relative humidity & Vaisala & WXT510 & +14.5 \\
Precipitation & Vaisala & WXT510 & +14.5 \\
Atmospheric pressure & Vaisala & WXT510 & +14.5 \\
\hline & Oceanographic measurements & \\
\hline Water temperature & Seabird & SBE39 & $-0.5,-12.0,-28.0$ \\
\hline & Service measurements & \\
\hline Geog. position (Lat/Lon) & Garmin & GPS16LVS & +10.6 \\
Heading & RMYoung & 32500 & +7.8 \\
Roll /Pitch & Planar Tech. GmbH & NS-15/V2I & -10.5 \\
\hline
\end{tabular}
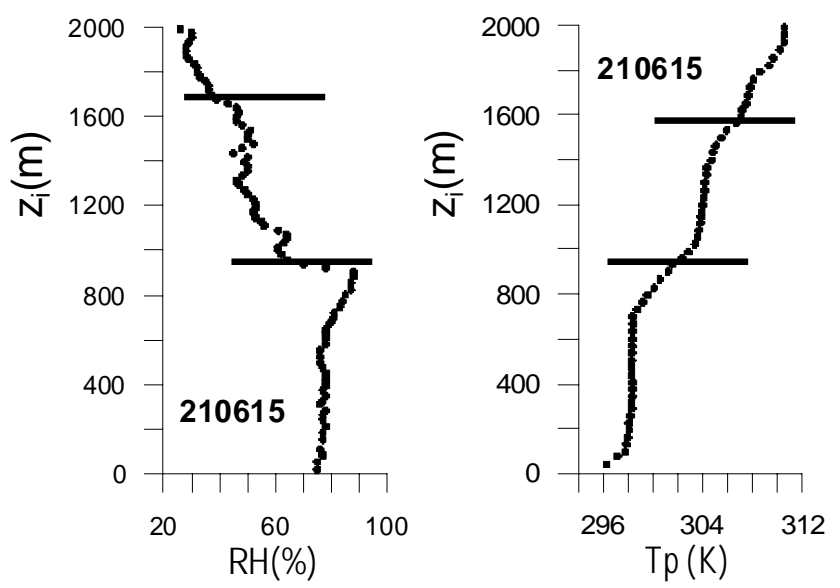

Fig. 2. Example of the detection of first and second inversion heights from radiosonde vertical profiles of Potential Temperature (right) and Relative Humidity (left) during 21 June 2007.

inversion, at about $1600 \mathrm{~m}$, a similar feature in both potential temperature and humidity vertical profiles is identified. The presence of this second inversion will be discussed in the following section.

Unfortunately, intensive radiosonding measurements are not easily available. Their high operational costs often limit their routine use over the ocean at synoptic hours. Therefore, during the last few years, remote sensing techniques, like acoustic (SODAR - SOnic Detection And Ranging), or optical (LIDAR - LIght Detection And Ranging) for continuously monitoring of the MABL structure, have been explored with success. Recently, ceilometers have been successfully employed for detecting the MABL height. Ceilometers incorporate diode laser based LIDAR technology, which allows an active range-resolved optical remote sensing measuring technique. A LIDAR transmits a laser pulses vertically (or close to vertical), and measures the backscattered signal that depends on the amount of scattering particles in a volume at a certain distance from the instrument.

The algorithms for retrieving the height of the inversion are based on the characteristic of the top of the MABL: the entrainment of dry air from the FA, clean from marine aerosols, into the moist air below; and the discontinuity in the air properties at the MABL-FA interface (Hayden et al., 1997; Flamant et al., 1997; Eresmaa et al., 2006; Hennemuth and Lammert, 2006; Münkel, 2007). Essentially, the high temporal variability of the entrainment process of warm and dry clean air leads to considerable fluctuations of the aerosols concentration then to a large variance in the optical backscatter. On the other hand, the low content of aerosols in the FA results in a large vertical gradient of the aerosolconcentration and then in a minimum scatter of the LIDAR signal. Therefore, the height of the maximum variance, and the height of the largest negative peak of the derivative of the optically attenuated backscatter intensity, can both be assumed as being the height of the MABL (Emeis et al., 2008). 


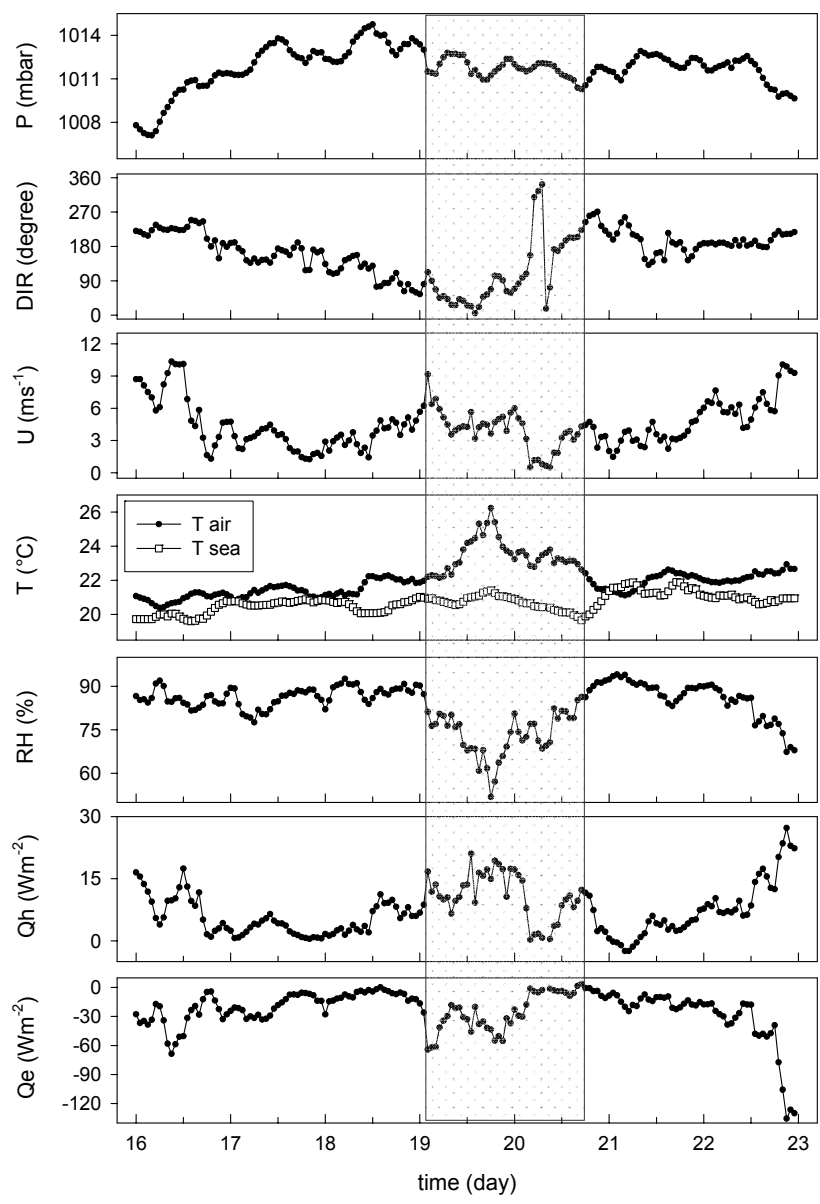

Fig. 3. From top to bottom, time series of the surface pressure $P$, wind direction DIR, wind speed $U$, air temperature $T_{\mathrm{a}}$ and sea temperature $T_{\mathrm{S}}$ (in the same plot), relative humidity $\mathrm{RH}$, Sensible heat flux $Q_{h}$ and latent heat flux $Q_{e}$ during LASIE. Note that positive values indicate downward fluxes. The shaded area corresponds to offshore flow that causes an increase of air temperature and the evolution of the vertical structure of the Marine Boundary Layer in Fig. 4.

In the following section, we show the evolution of surface flow characteristics, monitored at the ODAS buoy, and the simultaneous evolution of the vertical structure of the MABL, monitored by both the ceilometer and the radiosondes.

\section{Evolution of the vertical structure of the MABL dur- ing LASIE}

The intensive observation period of the LASIE experiment lasted seven days and was characterized by highly variable meteorological conditions, so that different atmospheric situations, affecting the development of the MABL structure, were observed.

Figure 3 shows the evolution of the surface parameters measured by the sensors mounted on the buoy $\left(U, \operatorname{Dir}, T_{\mathrm{a}}\right.$,
$\left.T_{\mathrm{S}}, \mathrm{RH}\right)$ and of the derived sensible and latent fluxes, $Q_{h}$ and $Q_{e}$, respectively, computed following the algorithm provided by Fairall et al. (1996), during the period from 16 June to 22 June. In Fig. 3, we use the convention that positive values indicate downward fluxes. Figure 4 shows the time-height cross section of the vertical structure of the MABL, in terms of vertical profiles of $T_{\mathrm{p}}$ (top) and $\mathrm{RH}$ (bottom), monitored by radiosondes from 17 June to 22 June and the heights of all the inversions estimated by visual inspection of the vertical profiles.

The impact of the change in wind direction on the entire MABL structure can be well observed in both Fig. 3 and Fig. 4. During the first day of the campaign (16 June) a low pressure system was centered over England, inducing large pressure gradients and strong winds over South England and North France. A second low was located over the Sahara Desert. The presence of these two low-pressure systems generated a predominant Southwestern flow throughout West Europe. Particularly, over the Ligurian Sea, the winds were relatively strong and from the Southwest. The sky was covered with a significant amount of low cumulus and the sea was rough. Although the wind speed was higher than $6 \mathrm{~m} \mathrm{~s}^{-1}$, the turbulent air-sea fluxes were low due to the small temperature and humidity gradients between air and sea, most likely due to the offshore long fetch traveling time of the air masses that induced the thermal equilibrium. During 17 June, the low pressure centered over England dissipated and a high pressure center formed over Italy, leading to a weak Southern flow over the Ligurian Sea region. The meteorological conditions improved, but a thin cover of high clouds was always observed. The turbulent air-sea fluxes were still close to zero due to the low wind speed. The surface conditions became more stable with increasing water vapor in the surface layer. The calm condition persisted until the late afternoon on 18 June, when a weak anticyclone formed over the Northern Italy, leading to a Northwestern offshore flow over the Ligurian Sea. In Fig. 3, we observe a consequent rapid decrease of the surface humidity, and an increase in air temperature, which became higher than the sea surface temperature. This situation resulted in large negative (downward) heat fluxes and stable conditions at the surface. In Fig. 4, we note the stable ground based inversion of the $T_{\mathrm{p}}$ profile at around $150 \mathrm{~m}$, which trap the moist along with a drop of the vertical RH, and a ML topped by a second inversion. Figure 4 is similar to Fig. 4a in Garratt and Ryan (1989) that shows the impact of an outbreak of warm and dry air from land, offshore of the southeast coast of Australia. Comparing $T_{\mathrm{p}}$ ground-based inversions, detected at three distances from cost, Garratt and Ryan (1989) found that the IBL can be observed up to $300 \mathrm{~km}$ reaching up to $400 \mathrm{~m}$ height at the longest fetch. According to Garratt and Ryan (1989), the ML above the inversion reflects the warm dry air advected from land. Therefore, we might conclude that in our case we observed an internal boundary layer developing from the coast. The IBL ground-based inversion was stationary until 


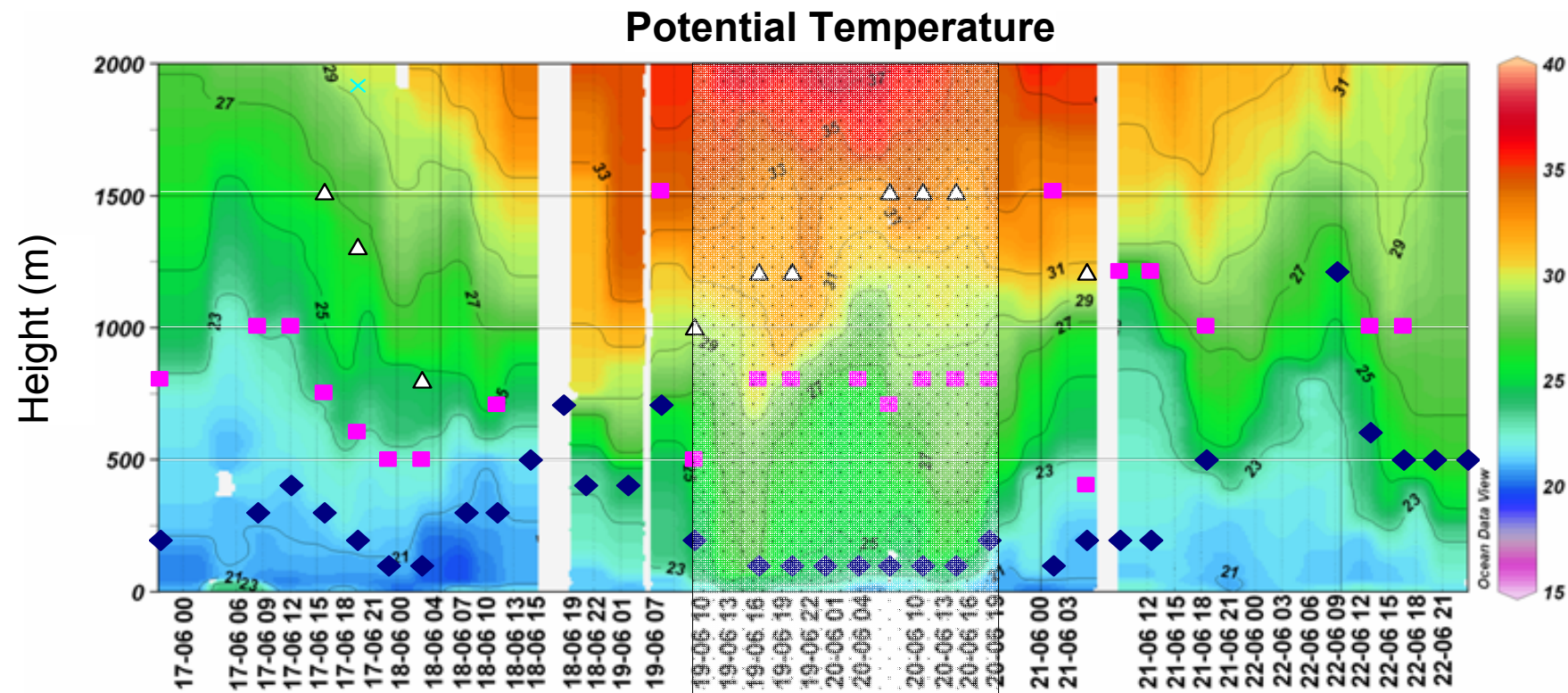

Relative Humiditv

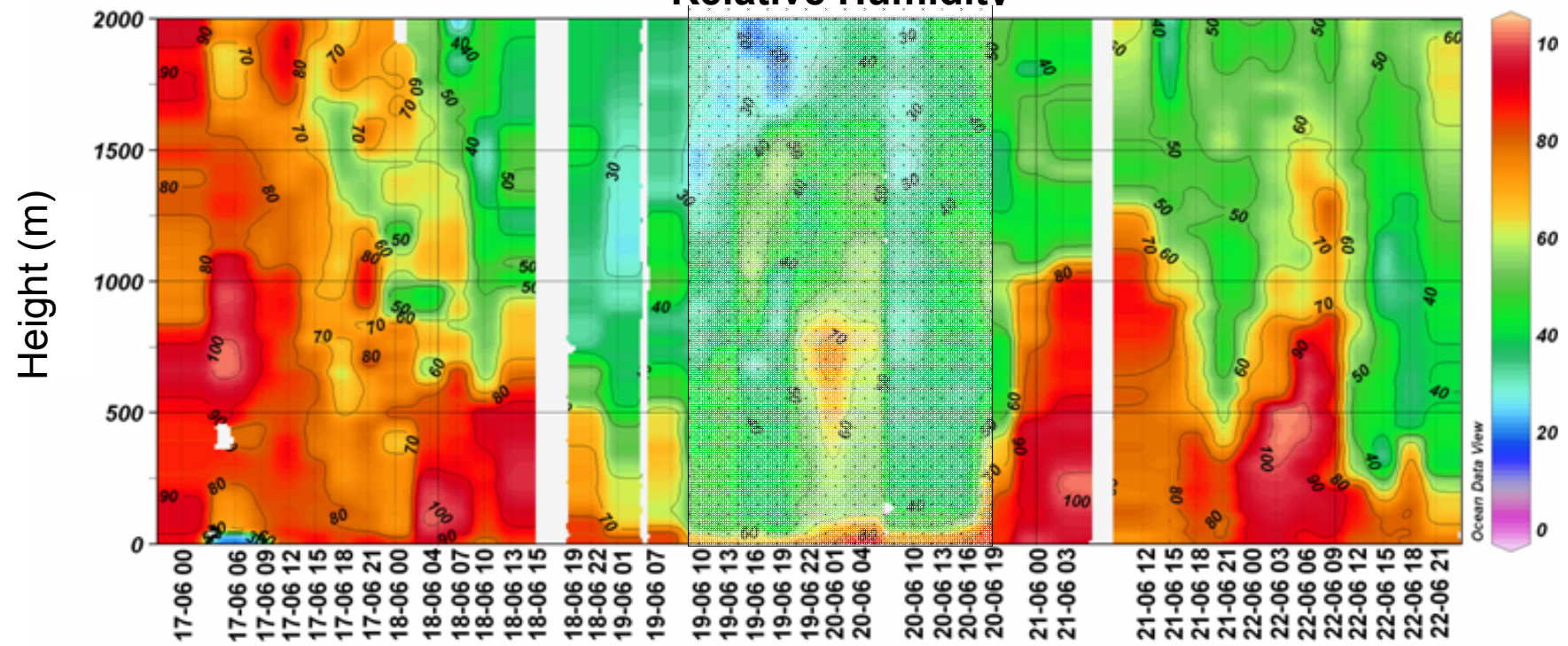

Time (Day-month-hour)

Fig. 4. In the top figure, we show the time-height cross section of the vertical structure of $T_{\mathrm{p}}\left({ }^{\circ} \mathrm{C}\right)$ and the heights of the inversions found by visual inspection. The bottom figure shows the vertical structure of RH(\%). These figures clearly show the impact of the changes in synoptic conditions on the vertical structure of the MABL during the period corresponding to the shaded area in Fig. 3. Multiple inversions can also be noted.

a weak instability occurred over the Ligurian Sea the afternoon on 20 June, where the wind direction started to slowly rotate from offshore to onshore, both wind speed and air temperature decreased while the humidity, mostly trapped in the surface layer, increased. The sky was clear, the sea was calm and the atmospheric stability alternated between stable and neutral. During 21 June and 22 June a low pressure center moved towards England. The winds rotated from Southwest to South and increased in intensity. The cloud cover was highly variable, with dense low clouds near the coast, and clear sky offshore. This depression influenced the meteorological conditions over the whole Europe until it dissipated later on 23 June. Over the Ligurian Sea this phenomenon determined the passage of a weak perturbation on 22 June, and near-neutral - stable conditions until the end of the experiment.

In Fig. 5, we consider only the four days, from 18 June to 21 June that include the $48 \mathrm{~h}$ with the onshore - offshore - 

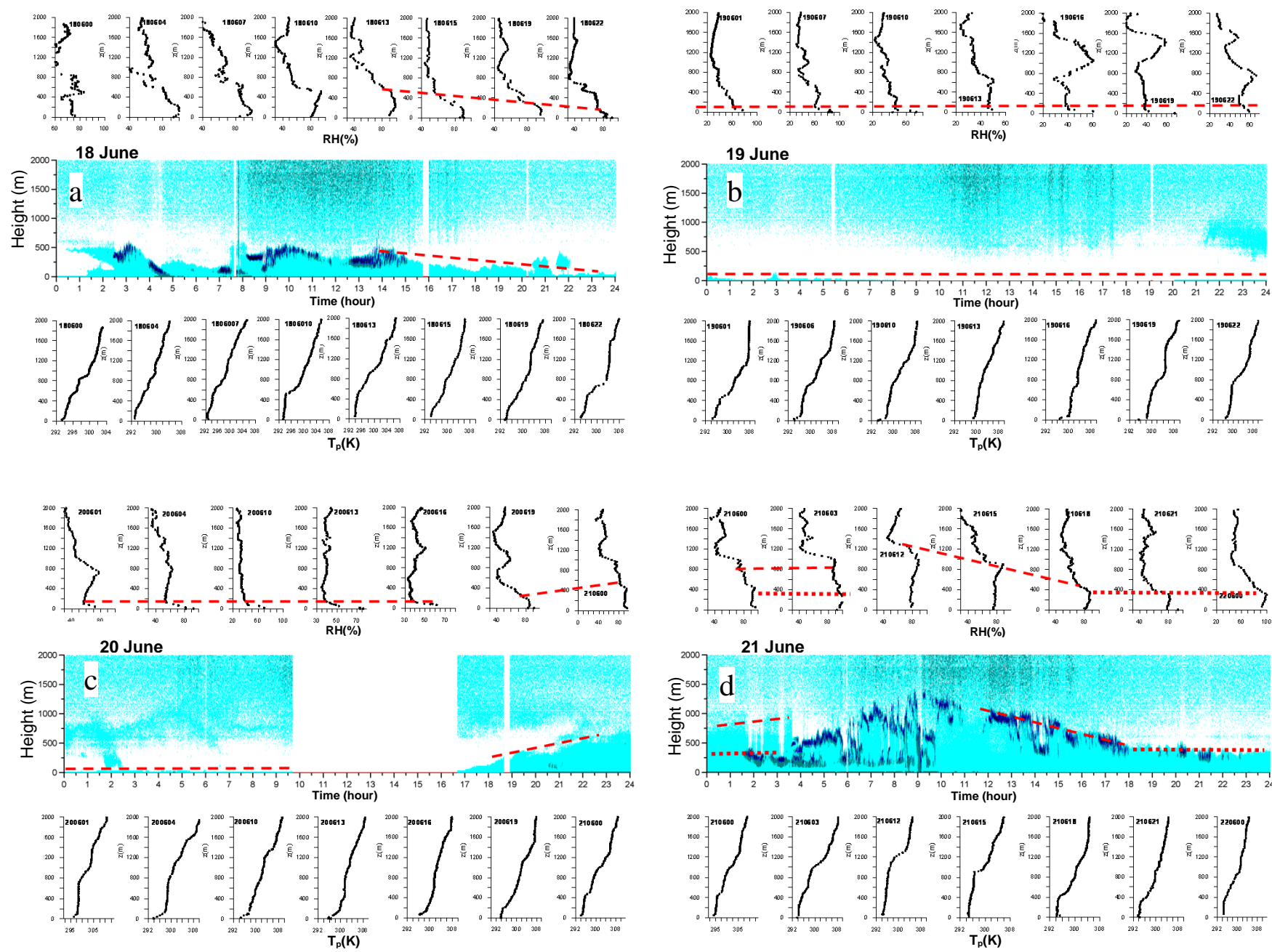

Fig. 5. Comparison of the development of the height of the MABL during 18 (a), 19 (b), 20 (c) and 21 (d) June 2007 from the ceilometer and single radiosonde profiles of $T_{\mathrm{p}}$ and $\mathrm{RH}$. In each figure, we show vertical profiles of relative humidity from radiosondes (top), backscatter from ceilometer (middle) and vertical profiles of $T_{\mathrm{p}}$ from radiosondes (bottom). Red lines show the behaviour of $z_{i}$ from the two systems. Note that in panels (b) and (c) the humidity is trapped at the surface by the ground-based $T_{\mathrm{p}}$ inversion.

onshore sequence of events. We show the time-height cross section of the ceilometer backscatter signal along with the time series of the single profiles of $T_{\mathrm{p}}$ and $\mathrm{RH}$ (equivalent to Fig. 4). The ceilometer backscatter intensity signal is in arbitrary units, where the dark blue colour indicates stronger backscatter in contrast to light blue. The darker colour in the middle of the day above $1500 \mathrm{~m}$ represents an effect of the sun light on the backscatter signal. We would like to point out an interesting difference between the schemes for estimating the inversion height from radiosoundings and optical backscatter intensities; this should be noted carefully because it can induce discrepancies in the comparisons. The LIDAR approach is based on the fact that the stable stratification at the surface and/or at the top of the mixing layer, usually confines aerosols in the ABL. Optical waves are scattered at small particles and the backscatter signal is propor- tional to the aerosol concentration itself (Emeis et al., 2008). The evaluation of $z_{i}$ from radiosondes is based on the temperature inversion. Therefore, here, we qualitatively compare the ceilometer signal to the height of the step decrease of water vapour, which can be considered as a proxy for marine aerosols concentration. The dotted and dashed lines in Fig. 5 indicate the evolution of $z_{i}$ and of the second inversion detected by both systems.

At the end of 18 June, (Fig. 5a) the wind turned offshore, following the low pressure system centred over South East France, and it remained offshore for a period of about 2 days. During this offshore flow, the sensors at the buoy recorded warm and dry air from land that, advected over a colder sea, induced a stable IBL. In Fig. 5a, we observe the adjustment of the vertical profiles of $T_{\mathrm{p}}$ and $\mathrm{RH}$ to the change in the atmospheric flow, from neutral to stable, by the lowering of the 
temperature inversion height. This is also well evident in the trend of the ceilometer backscatter profile. The ground-based inversion that caps the stable layer trapped the moist, and a second inversion was formed between 1200 and $1500 \mathrm{~m}$. The existence of a second inversion was noted by Sempreviva and Gryning (2000) who also produced seasonal statistics of its height analyzing more than 400 radiosoundings in Denmark, and by Johansson et al. (2005) in the Baltic Sea. Sempreviva and Gryning (2000) assumed two possible explanations: the second inversion might have been originated from the residual layer, which remained from the time the previous inversion reached that height, or the radiosondes might have recorded an ABL developed over land and advected over the sea. In the present case, since the height we detect $\left(z_{i}=1500 \mathrm{~m}\right)$ is higher than the inversion detected during onshore flow conditions, we believe that the second inversion might indicate an ABL advected from land, because the land ABL is generally higher than over the sea. Later in the night on 18 June, a ground-based inversion formed at about $100 \mathrm{~m}$ and kept constant for the next two days (Fig. 5b and c). On 19 June, the MABL collapsed (Fig. 5b). In this period, the ceilometer backscatter signal became very low due to low moisture content into the whole layer and no dry air entrainment. When the wind turned onshore, in the late afternoon on 20 June (Fig. 5c), vertical mixing started again and the ground based inversion height increased with time. The MABL continued to grow during the night of 21 June (Fig. 5d) and in the early morning, we observe a multi-layer structure of the MABL, mostly due to the presence of clouds. After 10:00 a well defined inversion develops but decreases during the remaining of the day.

Both radiosondes and ceilometer detected the lowering of the $z_{i}$ (dotted and dashed lines). We observe that the ceilometer backscatter is in very good agreement with the development of relative humidity vertical profiles but is generally not able to detect multiple structures in the potential temperature profiles.

\section{Conclusive remarks}

The purpose of the LASIE campaign was to contribute to understand the interaction between the MABL and the oceanic boundary layer at the air-sea interface, and to produce case studies for evaluating ocean-atmosphere coupled models and atmospheric models at different time and space scales. The combined database of surface and upper air parameters recorded during LASIE represent an uncommon experimental case study for the evolution of the Marine Atmospheric Boundary Layer.

In this paper, we have shown the development of the vertical structure of the MABL and of its height $z_{i}$ monitored by two instruments based on different principles: a ceilometer and radiosondes. Both instruments detected the MABL structure evolution, following the sequence onshore - offshore - onshore flow when the marine surface layer become stable and dry, as a consequence of warm and dry air advected from land over a colder sea that develop a stable Internal Boundary Layer. However, it appears that the ceilometer is not able to detect multiple structures in the potential temperature profiles above the first inversion.

It is clearly shown experimentally, for the first time in the Mediterranean area, how the vertical structure of the MABL changes according to changes in the synoptic conditions. The height of the MABL inversion was identified up to $1200 \mathrm{~m}$ and the IBL ground-based inversion at around $150-200 \mathrm{~m}$. Since the ship operational area was between 50 and $80 \mathrm{~km}$ offshore, the height of the IBL that we estimated is in agreement with the results from Garratt and Ryan (1989) that found an offshore IBL ranging 150 to $300 \mathrm{~m}$ at distances from the coast between $45 \mathrm{~km}$ and $165 \mathrm{~km}$. Above the stable MABL, we also detect a ML and a second inversion, which during offshore advection, might indicate the advection of an inversion developed over land, Garratt and Ryan (1989).

In Fig. 4, we note that often more than two inversions are detected. We believe that this might be due to the enclosed sea characteristics of the Ligurian Sea, where ABL from the surrounding land can be advected over the sea and detected for hundreds kilometers.

This case study fulfils the purposes of LASIE campaign: the atmospheric database, together with the oceanic measurements, are of great value for future evaluation of oceanatmosphere coupled model systems, and atmospheric models at different spatial and temporal scales. Moreover in the last decade, it became increasingly evident that the height of the MABL and its structure play a significant role on the surface turbulence, and on wind speed profiles. Therefore, we should also mention that high frequency measurements $(20 \mathrm{~Hz})$ of wind speed, temperature, moisture and $\mathrm{CO}_{2}$ were collected onboard of the URANIA; a Gill research sonic anemometer measured time series of wind speed $U$ components $u$, $v$, and $w$ and temperature $T$ to derive turbulent fluxes of momentum and heat; and a LICOR 7500 measured time series of humidity $q$ and carbon dioxide $\mathrm{CO}_{2}$ concentration to derive turbulent fluxes of moisture and $\mathrm{CO}_{2}$. However, flux estimates from a ship are not straightforward. Turbulent components of the wind speed must be either corrected from the movement of this platform using i.e. pitch, roll and heave measurements or using other methods based on the spectral analysis of the high frequency time series; therefore, this issue is object of an ongoing investigation. When turbulent fluxes at the surface become available, the database will be valuable to relate turbulent exchange of momentum heat and moisture at the surface to the development of the vertical structure of the MABL and to study the inter-play of processes at different time and space scales.

Acknowledgements. We thank the Italian CNR for the availability of R/V Urania during the dedicated cruise "LIGURE2007", coordinated by Sandro Carniel (CNR-ISMAR, Venice). The captain and crew of the N/O URANIA are also thanked for their excellent con- 
tributions to this successful campaign. We thank NURC for organizing the LASIE campaign and granting funding for shipping instruments and for the purchasing of radiosondes. Michael Courtney, Soeren Lund and Lars Christensen, from Risoe-DTU, are thanked for setting up the ceilometer acquisition system. Daniele Contini and Antonio Donadeo from CNR-ISAC Lecce, and Pedro Miranda from the Faculty of Sciences of the University of Lisbon, are also thanked for useful discussions on the paper. Alvaro Semedo and Ricardo Tomé acknowledge the funding from the FP6 Marie Curie Research Network ModObs MRTN-CT-2006-019369. Ricardo Tomé acknowledges funding from the Azores University, grant M3.1.1/I/010A/2005. The ModObs Network www.modobs. windeng.net has been one of the sponsors of the LASIE Campaign.

Topical Editor F. D'Andrea thanks two anonymous referees for their help in evaluating this paper.

\section{References}

Bertaux, H. O.: Buoy Enginering, John Wiley \& Sons, 1976.

Brooks, I. M., Goroch, A. K., and Rogers, D. P.: Observations of Strong Surface Radar Ducts over the Persian Gulf, J. Appl. Meteorol., 38, 1293-1310, 1999.

Cavaleri, L. and Mollo-Christensen, E.: Wave response of a spar buoy with and without a damping plate, Ocean. Engin., 8, 1724, 1981.

Edson, J., Crawford, T., Crescenti, J., Farrar, T., Frew, N., Gerbi, G., Helmis, C. Hristov, T., Khelif, D., Jessup, A., Jonsson, H., Li, M, Mahrt, L., McGillis, W., Plueddemann, A, Shen, L., Skyllingstad, E., Stanton, T., Sullivan, P., Sun, J., Trowbridge, J., Vickers, D., Wang, S., Wang, Q., Weller, R., Wilkin, J., Williams, A. J., Yue, D. K. P., and Zappa, C.: The Coupled Boundary Layers and Air-Sea Transfer Experiment in Low Winds, B. Am. Meteorol. Soc., 88, 341-356, 2007.

Emeis, S., Schäfer K., and Münkel, C.: Surface-based remote sensing of the mixing-layer height - a review, Meteorologische Zeitschrift, 17(5), 621-630, 2008.

Eresmaa, N., Karppinen, A., Joffre, S. M., Rsnen, J., and Talvitie, H.: Mixing height determination by ceilometer, Atmos. Chem. Phys., 6, 1485-1493, 2006, http://www.atmos-chem-phys.net/6/1485/2006/.

Fairall, C. W., Bradley, E. F., Rogers, D. P., Edson, J. B., and Young, G. S.: Bulk parameterization of air-sea fluxes for Tropical Ocean-Global Atmosphere Coupled-Ocean Atmosphere Response Experiment, J. Geophys. Res., 101(C2), 3747-3764, 1996.

Garratt, J. R. and Ryan, B. F.: The structure of the stably stratified internal boundary layer in offshore flow over the sea, Bound.Lay. Meteorol., 47, 1-4, 1989.

Gryning, S.-E. and Batchvarova, E.: Marine boundary layer and turbulent fluxes over the Baltic Sea: Measurements and modelling, Bound.-Lay. Meteorol., 103, 29-47, 2002.

Gryning, S.-E., Batchvarova, E., Brümmer, B., Jørgensen, H. E., and Larsen, S. E.: On the extension of the wind profile over homogeneous terrain beyond the surface boundary layer, Bound.Lay. Meteor., 124, 251-268, 2007.

Flamant, C., Pelon, J., Flamant, P. H., and Durand, P.: Lidar determination of the entrainement zone thickness at the top of the unstable marin atmospheric boundary layer, Bound.-Lay. Meteor., 83, 247-284, 1997.
Johansson, C., Hennemuth, B., Bösenberg, B., Linné, H., and Smedman, A.-S.: Double-layer structure over the Baltic Sea, Climatology, Case Study and Simulation, Bound. Lay. Meteor., 114, 389-412, 2005.

Katul, G. G., Sempreviva, A. M., and Cava, D.: The TemperatureHumidity Covariance in the Marine Surface Layer: A Onedimensional Analytical Model, Bound.-Lay. Meteor., 126, 263 278, 2008.

Kelsh, M., Caporali, E., and Lanza, L. G.: Hydrometeorology of flash floods, in: Coping with Flash Floods, NATO Science Series, edited by: Gruntfest, E. and Handmer, J., Kluwer Academic Pub., The Netherlands, 19-35, 2001.

Hayden, K. L., Anlauf, K. G., Hoff, R. M., Strapp, J. W., Bottenheim, J. W., Wiebe, H. A., Froude, F. A., Martin, J. B., Steyn, D. G., and Mckendry, I. G.: The Vertical Chemical and Meteorological Structure of the Boundary Layer in the Lower Fraser Valley during Pacific '93, J. Atmos. Environ., 31, 2089-2105, 1997.

Helmis, C. G.: An experimental case study of the mean and turbulent characteristics of the vertical structure of the atmospheric boundary layer over the sea, Meteorologische Zeitschrift, 16, 375-381, 2007. doi:10.1127/0941-2948/2007/0215.

Hennemuth, B. and Lammert, A.: Determination of the atmospheric boundary layer height from radiosonde and lidar backscatter, Bound.-Lay. Meteor., 120, 181-200, doi:10.1007/s10546-0059035-3, 2006.

Larsén, X. G. and Sempreviva, A. M.: Temperature and humidity dissimilarity in the marine surface layer, Solas News, Autumn 2008, 8, 12-13, 2008.

Münkel, C.: Mixing height determination with lidar ceilometers - results from Helsinki Testbed, Meteorologische Zeitschrift, 16(4), 451-459, 2007.

Nittis, K., Tziavos, C., Bozzano, R., Cardin, V., Thanos, Y., Petihakis, G., Schiano, M. E., and Zanon, F.: The M3A multi-sensor buoy network of the Mediterranean Sea, Ocean Sci., 3, 229-243, 2007, http://www.ocean-sci.net/3/229/2007/.

Schiano, M. E., Borghini, M., Castellari, S., and Luttazzi, C.: Climatic features of the Mediterranean Sea detected by the analysis of the longwave radiative bulk formulae, Ann. Geophys., 18, 1482-1487, 2000, http://www.ann-geophys.net/18/1482/2000/.

Schiano, M. E., Sparnocchia, S., Cappa, C., and Bozzano, R.: An analysis of the climate variability over the Mediterranean Sea by means of the surface water vapour density, Int. J. Climatol., 25, 1731-1748, 2005.

Seibert, P., Beyrich, F., Gryning, S.-E., Joffre, S., Rasmussen, A., and Tercier, P. H.: Review and Intercomparison of Operational Methods for the Determination of the Mixing Height, Atmos. Environ., 34(7), 1001-1027, 2000.

Sempreviva, A. M. and Gryning, S.-E.: Mixing height over water and its role on the correlation between temperature and humidity fluctuations in the unstable surface layer, Bound.-Lay. Meteorol., 97, 273-291, 2000.

Smedman, A.-S., Hogstrom, U., Hunt, J. C. R., and Salee, E.: Heat/mass transfer in the slightly unstable atmospheric surface layer, Q. J. Roy. Meteorol. Soc., 133, 37-51, 2007.

Stull, R.: An Introduction to Boundary Layer Meteorology, Kluwer Academic Press, Dordredht, 666 pp., 1988.

Teixeira, J.: Ligurian Air-Sea Interaction Experiment (LASIE) trial plan. NATO Undersea Research Centre, La Spezia, Italy, 30 pp, http://geos2.nurc.nato.int/mreaconf/ppt/3.0.pdf, 2007. 